\title{
Relationship between Self-concept Clarity and Generalised Pathological Internet Use among Undergraduates in Malaysia
}

Tam Kheng Hung, Rumaya Juhari

To Link this Article: http://dx.doi.org/10.6007/IJARBSS/v11-i11/11778

DOI:10.6007/IJARBSS/v11-i11/11778

Received: 02 September 2021, Revised: 04 October 2021, Accepted: 26 October 2021

Published Online: 14 November 2021

In-Text Citation: (Hung \& Juhari, 2021)

To Cite this Article: Hung, T. K., \& Juhari, R. (2021). Relationship between Self-concept Clarity and Generalised Pathological Internet Use among Undergraduates in Malaysia. International Journal of Academic Research in Business and Social Sciences, 11(11), 2597-2616.

\section{Copyright: @ 2021 The Author(s)}

Published by Human Resource Management Academic Research Society (www.hrmars.com)

This article is published under the Creative Commons Attribution (CC BY 4.0) license. Anyone may reproduce, distribute, translate and create derivative works of this article (for both commercial and non0-commercial purposes), subject to full attribution to the original publication and authors. The full terms of this license may be seen at: http://creativecommons.org/licences/by/4.0/legalcode

Vol. 11, No. 11, 2021, Pg. 2597 - 2616

Full Terms \& Conditions of access and use can be found at http://hrmars.com/index.php/pages/detail/publication-ethics 


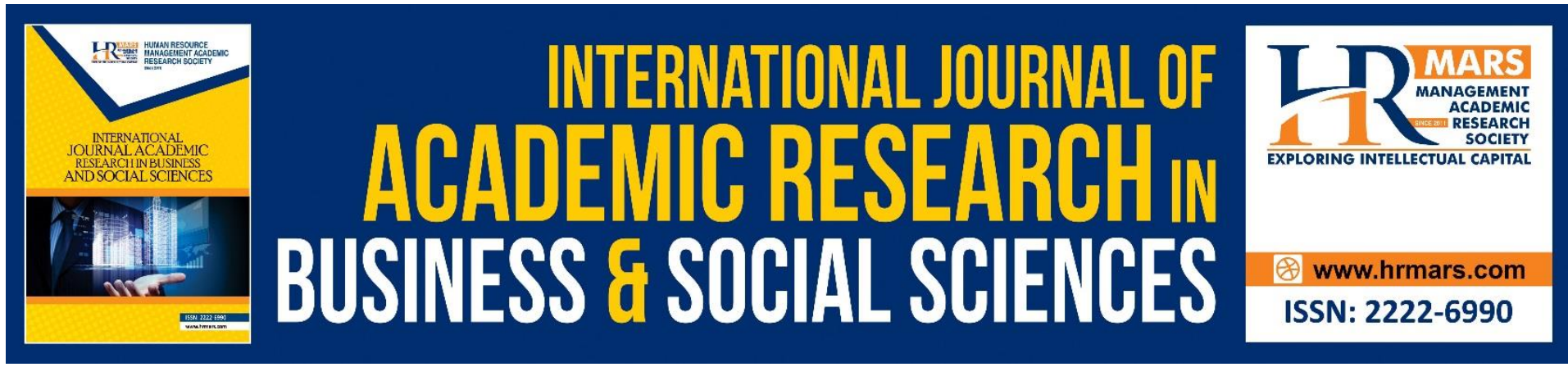

\title{
Relationship between Self-concept Clarity and Generalised Pathological Internet Use among Undergraduates in Malaysia
}

\author{
Tam Kheng Hung, Rumaya Juhari \\ Department of Human Development and Family Studies, Faculty of Human Ecology, \\ Universiti Putra Malaysia, 43400 UPM Serdang, Selangor, Malaysia \\ Email: tkhenghung@gmail.com, rumaya@upm.edu.my
}

\begin{abstract}
Generalised pathological Internet use (GPIU) is about the impact of social context on intensive Internet use. Previous studies found conflicting results in explaining this phenomenon among undergraduates with low self-concept clarity (SCC), in which they may utilise the social function of the Internet intensively to encounter the developmental task of informationseeking or social recognition. Since there are many young adults who use internet extensively, and studies in related field among undergraduates in Malaysia is at scarce, therefore the current study aims to examine the relationship between SCC and GPIU among undergraduates in Malaysia. A total of 480 undergraduates between the ages of 20 and 24 were recruited as respondents. Data were collected using a self-administered questionnaire with established instruments to measure the level of SCC and GPIU. Undergraduates with higher level of SCC had lower tendency to be involved in GPIU. Furthermore, SCC was the strongest predictor for GPIU, followed by number of hours spent on Internet per week and CGPA. Undergraduates in Malaysia exhibited interest to imply rich information and social platforms on Internet to improvise self-concept, rather than non-purposive usage of GPIU which need attention from related parties. The consistency of undergraduates pertaining to SCC warrant reinforcement.
\end{abstract}

Keywords: Self-concept Clarity, Generalised Pathological Internet Use, Cognitive-

Behavioural Model, Undergraduates, University

Introduction

\section{Background of The Study}

Internet Users Survey of Malaysia (Malaysian Communication and Multimedia Commission, 2020) testified that Internet users in Malaysia increased from $64.1 \%$ in year 2012 to $88.7 \%$ in year 2020. Internet users were most comprised of young adults in their twenties, where they accounted for 30\% in year 2018 (Malaysian Communication and Multimedia Commission, 2018) and had a big leap, which achieved $46 \%$ of the total population (Malaysian Communication and Multimedia Commission, 2020). In 2020, the commission revealed that parents' awareness of parental control decreased from $62.4 \%$ in year 2018 to $53.4 \%$ in year 
2020. The growing number of heavy Internet user who spent more than 12 hours on the Internet daily from $14 \%$ in year 2018 to $21 \%$ in year 2020 were also reported (Malaysian Communication and Multimedia Commission, 2020). These staggering findings alarmed local researchers to investigate this phenomenon, as Young (1999) discovered individuals who spent more than 12 hours per day or 38 hours per week on web browsing were considered as victims of Internet addiction.

However, despite the widespread usage of the Internet, the term 'Internet addiction' is somewhat of a misnomer (Davis, 2001). Although a consensual definition for Internet addiction is non-existent, however the term is broadly explained by researchers as a maladaptive pattern of Internet use (Spada, 2014; Laconi et al., 2014). To date, there is only one behavioural addiction disorder that is enlisted in Diagnostic and Statistical Manual of Mental Disorders, Fifth Edition (DSM-V), which is gambling (Sutapat et al., 2018). This could be explained by Young (1998) who has clarified that Internet addiction is different from the gambling habit as it is not intoxicative. Hence, the term "problematic Internet use" (Király et al., 2020, Asam et al., 2019; loannidis et al., 2018) and "pathological Internet use" (Kaess et al., 2021; Tong et al., 2019; Yu et al., 2018) were introduced. Existing local studies have highlighted the issue as "Internet addiction" (Kapahi et al., 2013; Roslan, 2015). Instead, the terms such as "problematic" and "pathological" were suggested to correct the concept from dependency on psychoactive substance to potentially pathological behavioural problem. In brief, the term "pathological Internet use (PIU)" as being used in this study, is the compatibility with primary focus of the theory's perspective, which explains the phenomena, that is not specifically influenced by the substances, but closely resembles the non-substances addiction, such as gambling disorder.

\section{Generalised Pathological Internet Use (GPIU)}

Davis (2001) developed the pathological Internet use (PIU) cognitive-behavioural model, who pioneered maladaptive cognitions (i.e. distorted thoughts and thought processes), as a proximal or direct causal of the set of symptoms of PIU, compared with the distal or nondirect causal, such as depression (Beck, 1976) and substance dependence (Kraut et al., 1998). To be differentiate cognitive behaviour from Internet addiction, the cognitive-behavioural model suggested that the study on PIU emphasises on the cognitive symptoms of an individual, such as diminished impulse control, inability to cease Internet usage, obsessive thoughts about the Internet, and the feeling of Internet as a mere companion (Davis, 2001). The terminology 'generalised pathological Internet use' (GPIU) in Davis (2001) model is also coined to describe the influence of social context of an individual on PIU, rather than solely maladaptive cognitive symptoms such as self-doubt, low self-efficacy and negative selfappraisal.

Davis (2001) explained that the model drawn on Skinner's (1948) Operant Conditioning Theory to explain the user experience of the Internet and novel technologies are reinforcements to a person who derive situational cues such as keyboard sound. Aligned with the development from Operant Conditioning Theory (Skinner, 1948) to Social Learning Theory (Bandura, 1977), the existence of meditational cognitive processes (i.e. observe, thought and imitate) between stimulus and response was highlighted, as the belief on humans are active information processors on considering consequences of the behaviour. Social cognitive theory (Bandura, 1986) then argued not solely either nature (biology) or nurture 
(environment) as the chief influence on human behaviour but interaction between both nature and nurture to provide emotion and social experience (i.e. beliefs, self-perceptions and expectations) can influence human behaviour. This explained the development of human dependencies behaviour from just content to the emotion and social experience which obtained from the provided social functions (such as 'Like' and 'Share' button in social media platform). Since the Internet offers various forms of social interaction and rewarding functions for its users, thus, it is crucial to understand the social effect of the Internet, such as the associated problematic use, negative effects from use, as well as indicators of psychosocial distress to the human being. On that account, GPIU is investigated in the present study so that the social context or environmental factor of the individual (Lopez-Fernandez, 2018) can be included in the study, rather than solely personal maladaptive cognitive symptoms relevant to the predictors.

An individual is tended to have GPIU while developing problems as the results of his or her preference in staying online as the communicative context. In another words, a person will be drawn to online experience, and has a penchant for virtual interpersonal communication contexts, compared to the kind of face-to-face in actual world (Caplan, 2002). Internet is used to communicate with largest imagination of user in its social role and also become the platform to contact with the outer world (Greenfield \& Yan, 2006). Thus, GPIU is often linked with the dependence of online chat and e-mail activities, which expected to have relations with social functions prepared in Internet. The outcome derived from the online demand for social contact and reinforcement is an increased desire to remain in a virtual domain type of social life (Davis, 2001). In conjunction with it, GPIU indicates an abnormal duration being online, either wasting time with unclear objective and no directive purpose, or spending much time in chat rooms to procrastinate their responsibilities (Davis, 2001). This wasted hour then results in serious issues affecting daily functioning by procrastinating responsibilities while the demands are not met (Davis, 2001). Consequently, some individuals may begin to feel guilty about their intense Internet usage. They began to realise and comprehend the reality of life and recognise that excessive Internet use is not only damaging their cognitive behaviour but also time consuming and they will not be able to cope with the lies to cover up their destructive compulsion. This may cause to diminish their self-worth and the vicious cycle eventually causes the individual to become detach from his or her social environment (Subrahmanyam et al., 2001). Thus, it is essential to examine the risks and protective factors for GPIU to avoid the involvement of people into the cycle.

GPIU is measured by the GPIU Scale 2 (GPIUS2), which outlined in year 2002 then revised by Caplan (2010) to measure the degree of a person encounter GPIU cognition, behaviours, and outcomes, which includes: (1) preference for online social interaction (POSI) (comprising of social benefits and a social control subscale), (2) mood regulation (previously known as mood alteration subscale), (3) deficient self-regulation (comprising subscales of cognitive preoccupation, or previously known as withdrawal, and compulsive use), and (4) negative outcomes with the exclusion of excessive Internet use subscale. On that account, GPIU is useful for investigating the indicators of psychosocial distress of individuals in the current study, particularly to evaluate the social functions of the Internet, whether or not it is linked with complex use and negative impacts of Internet use (Caplan, 2002). 


\section{Undergraduates and Generalised Pathological Internet Use (GPIU)}

The social impact of GPIU is observed in all age groups. However, the impact is greater among university students, who experience drastic developmental change from adolescence to young adulthood (Ceyhan, 2010). This stage is considered as a critical period of vulnerability to both substance and non-substance addictions. A young adult encounters the developmental task to interact with others, where information-seeking and social comparison are required too, and expected to involve in "developing closer relations" (Erikson, 1997). The online engagement is shown to create less anxiety compared "the real world" engagement. The anonymous of true identity and exclusion from the judgement of personal characteristics and appearance, are the motivators contributed to the attractiveness of online relations for young adults (Hall, 2001). The developmental characteristics also demonstrated by Ceyhan (2010) as contributor to the popular use of Internet among university students. Empirical evidence revealed that undergraduates who experienced GPIU tend to develop various adjustment problems, such as reduced academic performance (e.g. missing classes, reduction in study habits, and drop in grades), psychological well-being (retreat in relationships), social involvement (Chou et al., 2005), depression (Young, 1999), as well as university dropouts (Brady, 1997). Caldwell \& Cunningham (2010) consider the aforementioned conditions as the symptoms of problematic Internet use. The rise in university dropouts also has been linked with problematic Internet use (Brady, 1997) where the motivation of social recognition in Internet use was perceived as weakness amongst university students. This issue has become more worrying as evidence shows that addictive behaviours developed during this developmental period will probably remain the same into adulthood (Coffey et al., 2003).

Undergraduates being at a significant phase of their lives in terms of social and emotional development, are potentially at risk to fall prey on Internet dependence (Odaci \& Kalkan, 2010). This was later confirmed by another research group Pew Research Center (2012), who revealed that young adults (18-29 years) surfed the Internet longer than any other age groups. Moreover, research from other countries found that the 16-24 years old appeared as the highest Internet user age group (Öztürk et al., 2007). Within the Malaysian context, Internet Users Survey of Malaysia (Malaysian Communication and Multimedia Commission, 2018) testified that the highest age group distribution of Internet users in Malaysia is 20-24 years old across from year 2014 till 2018. On PIU statistics, approximately 63.3\% of private university students were identified as excessive Internet users (Haghighi et al., 2011), whereas $2.6 \%$ of public university students were found to be Internet-dependent (Hasmida et al., 2011). An existing report revealed that $43 \%$ of college students were identified to have PIU due to their excessive Internet abuse behaviour ( $\mathrm{Ng}$ et al., 2012), which were counterproductive to their lives. The study samples were found to spend 13.31 hours on the Internet every week. Notably, existing study reported that $13 \%$ to $18 \%$ of students attending public universities in Malaysia and the United Kingdom are in fact suffering from PIU (Haque et al., 2016). In another study among undergraduate students in a public university, $56.5 \%$ were identified as problematic Internet users (Rosliza et al., 2018).

Many studies have demonstrated that undergraduates aged from 18 to 24 are the highest consumers of the Internet. With the increasing number of Internet social platform and its underlying motivation of Internet use, which relates to this human developmental stage, there should be a comprehensive study among undergraduates in Malaysia. 


\section{Self-concept Clarity (SCC) and Generalised Pathological Internet Use (GPIU)}

Campbell (1990) proposed a structural measure of self-concept that was coined as selfconcept clarity (SCC). SCC is the extent to which the contents of the self are clearly and confidently articulated, consistent, and temporally stable. According to Campbell et al. (1996), low SCC levels are related to high levels of psychosis, low conscientiousness, low agreeableness, lasting self-contemplation, low internal state awareness and a ruminative form of self-focused attention.

An individual whose self-concept is vaguely defined may have greater tendency to abuse the Internet (Campbell et al., 1996). There are two ways to interpret this conjecture. First, individuals with low self-clarity do not possess a specific purpose in mind, thus waste unaccounted for time online. Marcia (1980) clarified that aimless and non-beneficial Internet overuse varies compared to individuals with a diffused identity. Additionally, Campbell et al. (1996) revealed individuals with low self-clarity are more likely to have high levels of selfanalysis and this indicates their excessive Internet usage too. The second interpretation proposed that excessive Internet usage is motivated by lack of clarity, which results in accessing the vast material found on the web to achieve higher self-clarity. Several studies concurred that strong needs and desires from an emerging adult to form clear, consistent, and coherent knowledge systems contributed significantly in shaping people's behaviour (VoJutabha et al., 2009; Inhelder \& Piaget, 1958).

According to Valkenburg and Peter (2011), there were two hypotheses, which are the selfconcept fragmentation and the self-concept unity that had been outlined to clarify the association of SCC with online communication. The fragmentation hypothesis explained the adolescents' personalities might be fragmented as a convenience in crafting online identities. Both studies of Reid (1998); Gergen (1991) clarified on the possible outcomes of new relationships formed online for people and ideas which further disintegrate the already fragile personalities. On the other hand, the self-concept unity hypothesis explained that adolescents were provided increased opportunities to interact with people from different backgrounds through the Internet. Consequently, adolescents can consolidate their identities against a widely expanded social sounding platform, which in turn may enhance their SCC (Calvert, 2002).

Findings from a total of three studies which investigated the effects of Internet on selfconcept clarity among adolescents found inconsistencies in their outcomes (Valkenburg \& Peter, 2008; Matsuba, 2006; Mazalin \& Moore, 2004). Two from the three studies exhibited that the frequency of Internet use or online identity experiments (i.e., pretending to be someone else) were associated with a lesser stable self-concept (Matsuba, 2006; Mazalin \& Moore, 2004). Whether or not the use of the Internet improves or hinders individual's SCC remains unclear. Therefore, this study explored the relationship between SCC and undergraduates' tendency toward GPIU.

In addition, multivariate analyses revealed the spuriousness of this association where other variables, such as loneliness and social anxiety (non-direct causal) were included in the model (Valkenburg \& Peter, 2008). Thus, linear regression was conducted in this study to examine the predicting effects of self-concept clarity. Hur (2006) defined the development of Internet addiction as an interactive process between personal demographic and socioeconomic 
backgrounds on personal habits of Internet usage. Thus, predicting effects of demographic variables on GPIU in this study among undergraduates in Malaysia should be further explored.

Based on the knowledge gaps of inconsistency explanation made on the relationship between SCC and GPIU and lack of literature on GPIU with the studied model in Malaysia, therefore this study aims to (1) determine the correlation between SCC with GPIU among undergraduates and (2) examine the predicting effects of SCC and demographic background (cumulative grade point average, hours spent online per week and household's monthly income) on GPIU among undergraduates.

\section{Methodology}

To trace the level of self-concept clarity that might affect the tendency of having GPIU amongst university students, the correlational design, with a quantitative approach using a cross-sectional survey method was used in this study.

\section{Participants}

The population of this study were undergraduate students from three universities which represented different urban regions within Malaysia. Through a non-probability convenient sampling, a total of 480 students who were between 20 and 24 years old (mean $=21.88$; SD $=1.16$ ) and actively enrolled in the degree programs were approached to participate.

\section{Procedure}

A standardised questionnaire was used to collect data from undergraduates. The first step was to seek approval from the Ethics Committee for Research Involving Human Subjects, Universiti Putra Malaysia in order to gain ethics clearance for the research process. The data collection activities were conducted over a three-month period from March till May 2017. Upon receiving the questionnaire, the respondents were given a short briefing on the objectives of the research to gain respondents' consent. Respondents were informed that participation is on a voluntary basis and all answers are confidential. It takes about 15 to 20 minutes to complete the questionnaire after which the respondents returned their questionnaire personally to the researcher. Respondents completed their questionnaires promptly without any issues and answered all questions so no follow-up questionnaires were made. The data collection process ended when an adequate number of respondents $(N=480)$ was achieved.

\section{Measures}

Self-concept Clarity (SCC). The Self-Concept Clarity Scale (SCCS; Campbell et al., 1991) which contains 12 items (e.g., "I spend a lot of time wondering about what kind of person I really am.") was used to measure the respondents' level of self-concept clarity. Respondents were asked to rank the extent to which how well each item describes them based on a 5-point Likert scale (1-"strongly disagree", 2-"disagree", 3-"neither agree nor disagree", 4-"agree", 5"strongly agree"). Most of the items in this section are negative i.e. items 1, 2, 3, 4, 5, 7, 8, 9, 10 and 12 . Thus, this means that a higher score for a negative question is reversed to a lower score. For example, score 1 was reversed to score 5 and score 2 was reversed to score 4 . In a previous study by Israelashvili et al (2012), after the deletion of one item, the Cronbach's alpha of the scale was 0.75 , with a higher score reflecting a higher level of self-clarity. The 
alpha reliability for the scale in the pilot study was 0.798 but was reported as 0.809 in the current study.

Generalised Pathological Internet Use (GPIU). The Generalised Problematic Internet Use Scale 2 (GPIUS2; Caplan, 2010) was used to measure the prevalence of cognitions, behaviours and the negative outcomes associated with GPIU in the study. The scale consists of 15 items, which include 5 unique sub-dimensions, each with 3 items: preference for online social interaction (item 1, 6, 11), mood regulation (item 2, 7, 12), cognitive preoccupation (item 3 , 8,13 ), compulsive Internet use (item 4, 9, 14) and negative outcomes (item 5, 10, 15) which are associated with Internet use. Respondents were asked to rank the extent to which how well each item described them on a 7-point Likert scale (1-"strongly disagree", 2-"disagree", 3-"slightly disagree", 4-"neutral", 5-"slightly agree", 6-"agree", 7-"strongly agree"). The intensity of GPIU cognitions, behaviours and negative outcomes was indicated by the strength of agreement. There is no negative item for this instrument. With regard to reliability, the five subscales derived from the items loading on each factor demonstrated high internal consistency scores, with Cronbach's alpha coefficients ranging from .82 to .87 and an overall of .91 (Caplan, 2010), with a higher score reflecting a higher level of GPIU. In a previous study (Assunção \& Matos, 2017), Cronbach's alpha of the scale was 0.91. The alpha reliability for the scale in the pilot study was 0.901 but was reported as 0.922 in the current study.

\section{Data Analysis}

Data obtained from questionnaires were analysed using Pearson Correlation and Linear Regression in SPSS 17.0. The results for the reliability tests were 0.809 and 0.922 for SCCS and GPIUS2 respectively. The instrument's particles have a number above $r$ table 0.7 , which indicates that the reliability and validity of the instrument was good for assessing the variables of this research (Creswell, 1994). Skewness values were 0.347 for self-concept clarity and 0.05 for GPIU indicating that both were within the acceptable limits $(-2$ and +2$)$ and had a normal distribution to perform Pearson correlation and linear regression. Descriptive analysis was used in this study to describe the demographic profile of respondents. The relations between SCC and GPIU was measured with bivariate correlation analysis. To determine the predictors for GPIU among undergraduates, linear regression was used. SCC, hours spent on Internet weekly and CGPA were entered in linear regression models.

\section{Findings}

\section{Descriptive Analysis}

The results of descriptive analysis of sociodemographic characteristics of the participants are depicted in Table 1 . The participants were undergraduate students from universities representing three regions in the country who were aged between 20 and 24 . While the mean age of the respondents was $21.88 \pm 1.16$, mean current CGPA of the respondents was 3.368 \pm 0.34 . This finding indicates that the respondents have a good academic achievement as the mean academic achievement is classified as the second upper class in the university. Most of the respondents $(73.9 \%)$ reported that their current CGPAs were in the second upper class. Only $15.5 \%$ and $10.6 \%$ of the respondents reported that their current CGPA were in first class and second lower class, respectively. 
Table 1

Socio-demographic characteristics of participants

Note: Sd. = Standard deviation

\begin{tabular}{|c|c|c|}
\hline Variable & $\mathbf{n}$ & $\%$ \\
\hline \multicolumn{3}{|l|}{ Age $(n=480)$} \\
\hline 20 & 60 & 12.5 \\
\hline 21 & 135 & 28.1 \\
\hline 22 & 130 & 27.1 \\
\hline 23 & 115 & 24.0 \\
\hline 24 & 40 & 8.3 \\
\hline \multicolumn{3}{|l|}{ Mean $=21.88 \quad$ Minimum $=20$} \\
\hline \multicolumn{3}{|l|}{ Maximum $=24$} \\
\hline \multicolumn{3}{|l|}{ CGPA $(n=414)$} \\
\hline$<3.000$ (Second class lower and below) & 44 & 10.6 \\
\hline $3.000-3.749$ (Second class upper) & 306 & 73.9 \\
\hline$\geq 3.750$ (First class) & 64 & 15.5 \\
\hline \multirow{2}{*}{$\begin{array}{ll}\text { Mean }=3.368 & \text { Minimum }=2.270 \\
S d . \quad=0.337 & \text { Maximum }=4.000\end{array}$} & & \\
\hline & & \\
\hline \multicolumn{3}{|l|}{ Hours spent on Internet per week $(n=442)$} \\
\hline$<22$ & 51 & 11.5 \\
\hline $22-49$ & 130 & 29.4 \\
\hline $50-84$ & 160 & 36.2 \\
\hline$>84$ & 101 & 22.9 \\
\hline \multicolumn{3}{|l|}{ Mean $=68.25 \quad$ Minimum $=4$} \\
\hline \multicolumn{3}{|l|}{ Sd. $=41.982$ Maximum $=168$} \\
\hline \multicolumn{3}{|l|}{ Household's monthly income $(n=394)$} \\
\hline$\leq \mathrm{RM} 2,848$ (Equal or lower than mean of $\mathrm{B} 40$ ) & 147 & 37.3 \\
\hline RM 2,848.01 - RM 6,502 (Equal or lower than mean of M40) & 147 & 37.3 \\
\hline RM 6,502.01 - RM 16,088 (Equal or lower than mean of T20) & 86 & 21.8 \\
\hline > RM 16,088 (Higher than mean of T20) & 14 & 3.6 \\
\hline \multicolumn{3}{|l|}{ Mean $=R M$ 5,257.50 Minimum $=R M 450$} \\
\hline Sd. $=R M 5,135.478$ Maximum $=R M 40,000$ & & \\
\hline
\end{tabular}

About $80 \%$ of the respondents claimed that their Internet usage was less than 84 hours per week. Nonetheless, $22.9 \%$ of the respondents spent more than 12 hours per day online and were considered as victims of Internet addiction (Young, 1999). The mean number of hours spent on the Internet per week reported from respondents was $68.25 \pm 41.98$. Notably, the mean value of Internet usage among the participants of the study is higher compared to the previous study which reported only 13.31 hours of average weekly Internet usage, where $43 \%$ came from the identified PIU college student respondents (Ng et al., 2012).

The household monthly income for the respondents' family ranges between RM450 and RM40,000, with a reported mean of RM5,257.50 $\pm 5,135.478$. Majority of the household's monthly income was considered to be equal or lower than the mean value of B40 and M40 
(74.6\%) in contrast to the mean of monthly income by household group in Malaysia (Department of Statistics Malaysia, 2017). This implies that the gadgets to access the Internet is unaffordable to families with lower socio-economic status. Notably, low family functioning (Ko et al., 2007) with poor communication (Yu \& Shek, 2013) may have a higher prevalence of PIU (Willoughby, 2008).

\section{Correlation Analysis}

Table 2 shows the result of Pearson correlation test. The results revealed that there was a significant negative correlation $(r=-0.459, p \leq 0.001)$ between self-concept clarity and generalised pathological Internet use (GPIU). Meaning the respondents who had lower selfconcept clarity reported higher incidence of GPIU. The strength of correlation between lower self-concept clarity and GPIU was strong.

Table 2

Correlations of independent variables with GPIU

\begin{tabular}{lcc}
\hline Variable & \multicolumn{3}{c}{ Generalised pathological Internet use (GPIU) } \\
\cline { 2 - 3 } & $\mathbf{r}$ & $\mathbf{P}$ \\
\hline Self-concept clarity & -0.459 & 0.000 \\
\hline
\end{tabular}

\section{Linear Regression Analysis}

The model was significant with $p$ value set at $p<0.001$, where the model explains $21.7 \%$ of variance in GPIU. Three significantly correlated variables (CGPA, number of hours spent online per week and SCC) and GPIU were entered into the regression model. Findings revealed that the regression model was significant $(F(3,382)=36.473, p<0.001)$. All three variables were statistically significant at different levels. Self-concept clarity $(\beta=-0.406, p<0.001)$ is the strongest predictor of GPIU, followed by the number of hours spent on the Internet per week $(\beta=0.187, p<0.001)$ and CGPA $(\beta=0.102, p<0.05)$.

Table 3

Regression analysis of CGPA, hours spent on Internet per week and SCC on GPIU Note: * Level of significant is at $p<.05 ; * * *$ Level of significant is at $p<.001$

\section{Discussions}

Relationship between Self-concept Clarity (SCC) on Generalised Pathological Internet Use

\begin{tabular}{lccc}
\hline Variable & \multicolumn{3}{c}{ Generalised Pathological Internet Use (GPIU) } \\
\cline { 2 - 4 } & B & \multicolumn{1}{c}{ SE.B } & Beta, $\boldsymbol{\beta}$ \\
\hline & & & \\
CGPA & 4.864 & 0.101 & $0.102^{*}$ \\
Hours spent on Internet per week & 0.071 & 0.017 & $0.187^{* * *}$ \\
Self-concept Clarity (SCC) & -0.909 & 0.101 & $-0.406^{* * *}$ \\
$\boldsymbol{R}^{\mathbf{2}}$ & & & \\
$\boldsymbol{A}$ djusted $\boldsymbol{R}^{\mathbf{2}}$ & & $0.223^{* * *}$ & \\
$\boldsymbol{F ( 3 , 3 8 2 )}$ & & $0.217^{* * *}$ & \\
\hline
\end{tabular}

(GPIU) 
The results from Pearson's correlation analysis suggest that negative correlation as those who had lower self-concept clarity (SCC) might have higher chances to suffer from GPIU. Campbell et al. (1996) revealed that individuals with low self-clarity were more likely to have high levels of self-analysis, and thus explains their excessive Internet usage. Caplan's (2010) study which proposed that individuals who were lonely, socially anxious or had deficient social skills (low SCC) would take online interpersonal interactions and relationships as an opportunity to have a safer, more efficacious, confident and comfortable social interaction rather than the traditional face-to-face social engagement. This can be defined as mood regulation behavioural symptom in GPIU. Caplan (2010) argued that Social Cognitive Theory of selfregulation from Bandura's (1991) study, where "anticipative affective reactions to ones' own behaviour" (p. 256) played a central role in the self-reactive process that governs selfregulations, to explain how social context affects individual's mood then predicts individual's cognitive ability in self-regulation in behaviour of Internet usage, in the instrument of GPIU Scale 2 (GPIUS2).

Another study (Morahan-Martin \& Schumacher, 2000) revealed similar observation that altered communication style was the main attraction for some of these excessive users. They found that Internet was more likely to be used to seek emotional support, chatting with others, and playing highly socially interactive games, as explained in social benefits of GPIU scale (GPIUS). Thus, the Internet could be an avenue for undergraduates in Malaysia to alleviate dysphoric moods or foster self-reactive outcome expectations so that their negative feelings were relieved. Bandura (2001) also explained that environmental innovations of increasing complexity, in turn, created new selection pressures for the evolution of cognitive capacities as well as specialised biological systems for functional consciousness, thought, language and symbolic communication. The existence of Internet environment where communal platforms are made much more accessible, changes individual's cognitive skills and behaviour. As a result, symptoms of preference for online social interaction (POSI) and cognitive preoccupation occurring with the ruminative focusing on ideal identity, result in GPIU behaviour (Caplan, 2010).

The current finding of undergraduates in Malaysia is consistent with several studies which suggested that fervent needs and desires from an emerging adult to form clear, consistent and coherent knowledge systems would significantly contribute in shaping people's behaviour (Vo-Jutabha et al., 2009; Inhelder \& Piaget, 1958). Haque et al (2016) stated that most of the time of a Malaysian university student spends most of his or her time on the Internet for both academic and extracurricular purposes. The current finding on high CGPA and Internet usage among undergraduates exhibited a predominant factor which motivated undergraduates online were because of their tendency as information and knowledge seekers, bagging the findings from Lu and Yeo (2015). Thus, the hypothesis on self-concept unity was identified where undergraduates who had a constant need to validate their identity, do so via the activities online in order to expand their social network. The identified hypothesis explains the long online duration spent by the intense users to seek for self-clarity are to pursue positive developmental goals, such as promotion of self-concept clarity and selfconsciousness, which in turn assist them in acquiring a sense of individuality and unity in the world (Valkenburg \& Peter, 2011). This could be explained by an existing study which found freshmen in Taiwan who had lower levels of ego development spent more than 10 hours per week on the Internet (Huang, 2006). The potential contribution of Internet anonymity to 
gratify the needs of intense users has been revealed by other researchers (Hinduja \& Patchin, 2008; Allison et al., 2006). Internet not only serves as a motivation medium for implementing their ideal selves, but also to explore alternatives of their current ego or self-perceptions. Meanwhile, the positive power of the Internet has been described as a way to expand knowledge about the world (Jensen, 2003) or way to find new attachment figures (Lei \& Wu, 2007). The current finding proves the interpretation that excessive Internet usage by undergraduates is motivated by a lack of clarity from diffused identity which resulted in utilisation of infinite material found on the web to attain greater self-clarity.

Current findings revealed that majority of the university undergraduates' household monthly income in Malaysia was measured to be equal or lower than the average household income of the B40 and M40 categories, respectively. Consequently, developmental stressor motivates the undergraduates to browse the Internet which is made available on campus. Two previous studies presented low stable self-concept (Matsuba, 2006; Mazalin \& Moore, 2004 ) is associated with the frequency of being online and using anonymity instead of their real identities (Hinduja \& Patchin, 2008). This is due to the fact that the Internet can motivate undergraduates in helping to identify their true self-worth as well as to explore other alternatives to boost their self-esteem to compete with their peers. Teo (2001) described that while perceived ease of use and perceived enjoyment were related to messaging, browsing, and downloading activities, perceived usefulness was linked solely to academic activities. According to Davis (2001), Operant Conditioning Theory (Skinner, 1948) explained that the positive experiences from using the Internet such as the response sound from social media platforms can also serve as a reinforcement to increase undergraduates' Internet usage. Consequently, undergraduates in Malaysia, especially in urban areas, consolidate their identities against a widely expanded social sounding platform online, which in turn may enhance their SCC, rather than non-purposive usage as introduced in GPIU.

In brief, undergraduates in Malaysia experienced a higher urge to form clear, consistent and coherent knowledge systems within the society thus exhibited high interest to imply infinite information and social platform on the Internet to improvise self-concept, rather than nonpurposive usage of GPIU which is pursued for dire attention from related parties.

\section{Self-concept Clarity (SCC), Numbers of Hours Spent on Internet Weekly and Cumulative Grade Point Average (CGPA) As Predictor of Generalised Pathological Internet Use (GPIU)} Regression analysis found the significant predicting effects of SCC, followed by the number of hours spent on the Internet weekly and CGPA. On the whole, the findings from this study are comparable with Sutapat et al (2018) who found that loneliness and interpersonal problems were factors that contributed to higher levels of addiction to the Internet among students in Chiang Mai. Inexplicably, approximately $57 \%$ of the variance among Internet addiction remain unexplained. Apart from the coherence in the findings from Sutapat's study and this study, another older study supported the current multivariate analysis results which found that the spuriousness of this association was caused by other variables such as loneliness and social anxiety from the model (Valkenburg \& Peter, 2008). The current model reflected GPIU instead of Internet addiction in the Malaysian context. As suggested by Davis's model (2001), loneliness and other interpersonal challenges such as depression are distal contributors to GPIU. Data from this study suggests that self-concept clarity as the most significant predictor 
which validates Davis's model (2001) interpreting self-concept clarity is in fact a proximal contributor toward GPIU among undergraduates in Malaysia.

The theoretical model did not mention the antecedent variables. However, current findings reflected the influence of both CGPA and number of hours spent online per week on GPIU. This is consistent with the description by Bandura (2001) denoting the behaviour of undergraduates was influenced by socio-demographic factors. The current finding also further expounds that environmental influence affected the psychological mechanisms of the undergraduates' self-system such as the interaction between human and environment as proposed by the social cognitive theory. This could be rationalised when self-concept clarity was found to be highly associated with the socio-economic status as well as family structures of these undergraduates. For instance, the equal or below average household income status of undergraduates predicts their preference in using cheap and informative Internet to persist on hardship for self-achievement in search of solutions to unravel academic challenges, thus resulting in GPIU when their attempts to control their screen time fails. These sociodemographic factors have a direct effect onto the behaviour of an individual (Bandura, 2001). Thus, variables, CGPA and number of hours spent online per week warrants more investigation to conceptualise a theoretical model which is culturally relevant in a context for Malaysia.

The results from this study revealed that CGPA of these undergraduates was able to predict GPIU. This is consistent with a previous study which was also conducted in Malaysia that found a significant association ( $p=0.003$ ) between CGPA and Internet usage (Siraj et al., 2015). This was very likely because students were assessed by their academic grades for better employment opportunities (Ibrahim, 2003). And so CGPA became a critical preliminary bench mark to qualify for the job market. Subsequently, undergraduates in Malaysia heavily depended on the Internet which is free and widely-accessible on campus to not only search for job opportunities but also to keep them abreast academically. Anand and Devi (2012) reported competition between peer plays a role in affecting the academic stress among undergraduates. The stressor become catalyst for undergraduates to surf the Internet to access infinite information to accomplish their assignments or to get linked to better social network. Even so, undergraduates with higher CGPA tend to have placed higher demands and expectations on themselves, thus often predisposed to chronic self-analysis and ruminative form of self-focused attention resulting in GPIU. And so, this finding exposed the risk of high achievers abusing the Internet due to the self-inflicted pressure to do better. In brief, correlation between CGPA and GPIU among undergraduates in this country should be further explored to add to the literature within the context of Malaysia.

The long duration of Internet usage becomes abnormal or unhealthy when the users lose track of time and are willing to sacrifice their rest time to make up for their loss. Thus, the time spent on Internet per week is also a predictor for GPIU. Undergraduates were found to spend an average of 68.25 hours in a week surfing the Internet. This finding revealed similar results for undergraduates in Malaysia, compared with students in Chiang Mai, Thailand (Wanajak, 2011). Results from this study were similar with previous studies in Malaysia where a considerable amount of time was spent by university students surfing the Internet too (Khan \& Magdalene, 2016; Salehi et al., 2014; Nurhilyana et al., 2013; Haghighi et al. 2011; Hasmida et al., 2011). Teong and Ang (2016) also informed that excessive participation in interactive 
functions on the Internet have higher association with Internet addiction. In GPIU, the excessive participation in interactive function on the Internet could be classified as a symptom of POSI and deficient self-regulation. The current finding revealed that undergraduates in Malaysia could be attracted to the various interactive functions available on social media platforms as well as applications on the Internet such as photo editing, video posting, comments via gifs to name a few, which assist in better self-expression and information sharing. All these Internet applications provide better experience to the users and in return get them hooked to innovate means to respond in more creative ways, resulting in unaware of the time lost. The online activity of the undergraduates was not explored in this study. Thus, a comprehensive investigation on the length of time spent online and their Internet usage pattern of online experience and online frequency is warranted for future research to support the correlation between long duration Internet usage and GPIU and determine the most related GPIU symptoms among undergraduates in Malaysia.

\section{Conclusion}

The results from this current study highlighted the significant role of self-concept clarity (SCC) towards the development of GPIU among undergraduates. The findings revealed that a correlation between SCC and GPIU may contribute to the existing body of literature on GPIU among undergraduates in Malaysia by highlighting the stronger needs and desires from young adults to a form clear, consistent and coherent knowledge system, thus significantly contributing in shaping people's behaviour (Vo-Jutabha et al., 2009; Inhelder \& Piaget, 1958) as social demands may be gratified through the Internet (Ko et al., 2009; Wallace, 2014).

Socio-demographic variables of the respondents including having a second class upper of CGPA, low financial support and higher average number of hours spent on the Internet weekly, represented the background of undergraduate students in Malaysia. This translated to better academic performance settings intended for undergraduates who are undergoing a precipitous developmental phase seeking their identity and building communication network rather than harbouring negative beliefs about themselves, their surroundings as well as maintaining self-environment relationships (Davis, 2001; Kaliszewska-Czeremska, 2011). On the contrary, undergraduates who have limited financial resources seek alternatives through the means of the Internet. Maladaptive cognitions from GPIU such as "self-focused rumination", "self-doubt", "low self-efficacy" and "negative self-appraisal" were generally low among respondents. However, prevention programs such as counselling sessions, seminars to manage time, finances, Internet usage, and social expenses were found to be beneficial in preventing this addiction problem from deteriorating.

Findings from the regression analysis showed that the self-concept clarity was the key predictor, followed by number of hours spent on the Internet weekly and CGPA as significant predictors for GPIU among the population of this study. These substantial correlations can be suggested for future studies of GPIU to enhance Davis's cognitive behavioural model (2001), align with social cognitive theory (Bandura, 1986) which argued interaction between both nature (cognitive) and nurture (environment) to experience emotions and social experiences (i.e. beliefs, self-perceptions and expectations) that ultimately influences an individual's behaviour (behaviour). This argument may act as reference for further studies to elaborate the explanation about correlation between SCC and GPIU, especially within the five constructs of GPIU, which are; the preference for online social interaction (POSI), mood 
regulation, cognitive preoccupation, compulsive Internet use and negative outcome, to determine possible intermediate associations within the model.

\section{References}

Asam, A. E., Samara, M., \& Terry, P. (2019). Problematic internet use and mental health among British children and adolescents. Addictive Behaviors, 90, 428-436. https://doi.org/10.1016/j.addbeh.2018.09.007

Allison, S. E., von Wahlde, L., Shockley, T., \& Gabbard, G. O. (2006). The development of the self in the era of the Internet and role-playing fantasy games. The American Journal of Psychiatry, 163(3), 381-385. https://doi.org/10.1176/appi.ajp.163.3.381

Anand, N., \& Devi, N. (2012). Academic stress in relation to self-efficacy and peer relations among college students. Journal of Health and Wellbeing, 3(3), 735-736.

Assunção, R. S., \& Matos, P. M. (2017). The Generalised Problematic Internet Use Scale 2: Validation and test of the model to Facebook use. Journal of Adolescence, 54, 51-59. https://doi.org/10.1016/j.adolescence.2016.11.007

Bandura, A. (1977). Social learning theory. Englewood Cliffs, NJ: Prentice Hall.

Bandura, A. (1986). Social foundations of thought and action: A social cognitive theory. Prentice Hall, Inc.

Bandura, A. (1991). Social cognitive theory of self-regulation. Organizational Behavior and Human Decision Processes, 50, 248-287.

Bandura, A. (2001). Social cognitive theory: An agentic perspective. Annual Review of Psychology, 52, 1-26. https://doi.org/10.1146/annurev.psych.52.1.1

Beck, A. T. (1976). Cognitive therapy and the emotional disorders. New York: International University Press.

Brady, K. (1996, April 21). Dropout rise a net result of computers. The Buffalo News, p. A1. https://buffalonews.com/news/dropout-rise-a-net-result-ofcomputers/article_5119c587-32b7-5711-857d-d77dabe10288.html

Caldwell, C. D., \& Cunningham, T. J. (2010). Internet addiction and students: Implications for school counselors. https://www.counseling.org/docs/defaultsource/vistas/vistas_2010 _article_61.pdf?sfvrsn=9f4a95cc_11

Calvert, S. L. (2002). Identity construction on the Internet. In S.L. Calvert, A.B. Jordan, R.R. Cocking (Eds.). Children in the digital age: Influences of electronic media on development (pp. 57-70). Westport, CT: Praeger.

Campbell, J. D. (1990). Self-esteem and clarity of the self-concept. Journal of Personality and Social Psychology, 59(3), 538-549. https://doi.org/10.1037/0022-3514.59.3.538

Campbell, J. D., Katz, I. M., Lavallee, L. F., \& Trapnell, P. D. (1991, June). Development and validation of a self-report scale of self-concept clarity [Conference presentation]. Annual Conference of the American Psychological Society, Washington, DC.

Campbell, J. D., Trapnell, P. D., Heine, S. J., Katz, I. M., Lavallee, L. F., \& Lehman, D. R. (1996). Self-concept clarity: measurement, personality correlates, and cultural boundaries. Journal of Personality and Social Psychology, 70(1), 141-156. https://doi.org/10.1037/0022-3514.70.1.141

Caplan, S. E. (2002). Problematic Internet use and psychosocial well-being: Development of a theory-based cognitive behavioural measurement instrument. Computers in Human Behavior, 18, 553-575. https://doi.org/10.1016/S0747-5632(02)00004-3 
Caplan, S. E. (2010). Modelling excessive Internet use: Revision of R. Davis's CognitiveBehavioural Model of Pathological Internet Use. Polish Psychological Bulletin, 42(3), 129-139. https://doi.org/10.2478/v10059-011-0018-6

Ceyhan, E. (2010). Predictiveness of Identity Status, Main Internet Use Purposes and Gender on University Students' Problematic Internet Use. Educational Sciences Theory \& Practice, 10(3), 1323-1355.

Chou, C., Condron, L., \& Belland, J. C. (2005). A review of the research on Internet addiction. Educational Psychology Review, 17(4), 363-388. https://doi.org/10.1007/s10648-0058138-1

Coffey, C., Carlin, J. B., Lynskey, M., Li, N., \& Patton, G. C. (2003). Adolescent precursors of cannabis dependence: Findings from the Victorian adolescent health cohort study. The British Journal of Psychiatry, 182, 330-336. https://doi.org/10.1192/bjp.182.4.279-a15

Creswell, J. W. (1994). Research design: Qualitative and quantitative approaches. Thousand Oaks, CA: Sage.

Davis, R. A. (2001). A cognitive-behavioural model of pathological Internet use. Computers in Human Behavior, 17, 187-195. https://doi.org/10.1016/S0747-5632(00)00041-8

Davis, R. A., Flett, G. L., \& Besser, A. (2002). Validation of a new scale for measuring problematic Internet use: Implications for pre-employment screening. CyberPsychology \& Behavior, 15, 331-347. https://doi.org/10.1089/109493102760275581

Department of Statistics Malaysia. (2017). Report of Household Income and Basic Amenities Survey 2016.

https://www.dosm.gov.my/v1/index.php?r=column/pdfPrev\&id=RUZ5REwve U1ra1hGL21JWVIPRmU2Zz09

Erikson, E. H. (1997). Life cycle completed. New York: W. W. Norton.

Gergen, K. J. (1991). The saturated self: Dilemmas of identity in contemporary life. New York, NY: Basic Books.

Greenfield, P., \& Yan, Z. (2006). Children, adolescents, and the internet: a new field of inquiry in developmental psychology. Developmental Psychology, 42, 391-394. https://doi.org/10.1037/0012-1649.42.3.391

Haghighi, B. T., Othman, M., \& Hashim, F. H. (2011, November 14-16). Internet addiction and dependency: A case study in UNITEN [Conference presentation]. International Conference on Information Technology and Multimedia (ICIM) 2011, Kuala Lumpur, Malaysia.

Hall, A. S. (2001). Internet addiction: College student case study using best practices in cognitive behavior therapy. Journal of Mental Health Counseling, 23(4), 312-327.

Haque, M., Rahman, N. A. A., Majumder, M. A. A., Haque, S. Z., Kamal, Z. M., Islam, Z., Haque, A. T. M. E., Rahman, N. I. A., \& Alattraqchi, A. G. (2016). Internet use and addiction among medical students of Universiti Sultan Zainal Abidin, Malaysia. Psychology Research and Behavior Management, 9, 297-307.

Hasmida, J., Zauwiyah, A., \& Noorhazreen, Z. (2011, October). Exploratory study on Internet addiction among varsity students in Malaysia [Conference presentation]. International Conference on e-Commerce, e-Administration, e-Society, e Education, and eTechnology (e-CASE \& e-TECH) 2011, Toshi Center, Tokyo, Japan.

Hinduja, S., \& Patchin, J. W. (2008). Personal information of adolescents on the Internet: a quantitative content analysis of MySpace. Journal of Adolescence, 31(1), 125-146. https://doi.org/10.1016/j.adolescence.2007.05.004 
Huang, Y. -R. (2006). Identity and intimacy crises and their relationship to Internet dependence among college students. CyberPsychology \& Behavior, 9(5), 571-576. https://doi.org/10.1089/cpb.2006.9.571

Hur, M. H. (2006). Demographic, habitual, and socioeconomic determinant of Internet addiction disorder: An empirical study of Korean teenager. CyberPsychology \& Behavior, 9(5), 514-25.

Ibrahim, A. B. (2003). Kompetensi pelajar menghadapi pasaran pekerjaan [Conference presentation]. International Conference on Measurement and Evaluation in Education, Universiti Sains Malaysia, Pulau Pinang, Malaysia.

Inhelder, B., \& Piaget, J. (1958). The growth of logical thinking from childhood to adulthood. New York: Basic Books.

Ioannidis, K., Treder, M. S., Chamberlain, S. R., Kiraly, F., Redden, S. A., Stein, J., Lochner, C., \& Grant, J. E. (2018). Problematic internet use as an age-related multifaceted problem: Evidence from a two-site survey. Addictive Behaviors, 81, 157-166. https://doi.org/10.1016/j.addbeh.2018.02.017

Israelashvili, M., Kim, T., \& Bukobza, G. (2012). Adolescents' over-use of the cyber world Internet addiction or identity exploration? Journal of Adolescence, 35, 417-424.

Jensen, L. A. (2003). Coming of age in a multicultural world: globalization and adolescent cultural identity formation. Applied Developmental Science, 7(3), 189-196.

Kaess, M., Klar, J., Kindler, J., Parzer, P., Brunner, R., Carli, V., Sarchiapone, M., Hoven, C. W., Apter, A., Balazs, J., Barzilay, S., Bobes, J., Cozman, D., Gomboc, V., Haring, C., Kahn, J-P, Keeley, H., Meszaros, G., Musa, G. J., . . .Wasserman, D. (2021). Excessive and pathological Internet use - Risk-behavior or psychopathology? Addictive Behaviors, 123, Article 107045. https://doi.org/10.1016/j.addbeh.2021.107045

Kaliszewska-Czeremska, K. (2011). Modeling excessive Internet use: Revision of R. Davis's Cognitive-Behavioural Model of Pathological Internet Use. Polish Psychological Bulletin, 42(3), 129-139.

Kapahi, A., Ling, C. S., Ramadass, S., \& Abdullah, N. (2013). Internet addiction in Malaysia causes and effects. I-Business, 5(2), 72-76.

Khan, V. T., \& Magdalene, C. H. A. (2016). Internet use and addiction among students in Malaysian public universities in East Malaysia: Some empirical evidence. Journal of Management Research, 8(2), 31-47. https://doi.org/10.5296/jmr.v8i2.9092

Király, O., Potenza, M. N., Stein, D. J., King, D. L., Hodgins, D. C., Saunders, J. B., Griffiths, M. D., Gjoneska, B., Billieux, J., Brand, M., Abbott, M. W., Chamberlain, S. R., Corazza, O., Burkauskas, J., Sales, C. M. D., Montag, C., Lochner, C., Grünblatt, E., Wegmann, E., . . .Demetrovics, Z. (2020). Preventing problematic internet use during the COVID-19 pandemic: Consensus guidance. Comprehensive Psychiatry, 100, 152-180. https://doi.org/10.1016/j.comppsych.2020.152180

Ko, C. H., Yen, J. Y., Chen, C. S., Yeh, Y. C., \& Yen, C. F. (2009). Predictive values of psychiatric symptoms for Internet addiction in adolescents: a 2-year prospective study. Archives Paediatric Adolescence Medicine, 163, 937-943.

Ko, C. H., Yen, J. Y., Yen, C. F., Lin, H. C., \& Yang, M. J. (2007). Factors predictive for incidence and remission of Internet addiction in young adolescents: A prospective study. CyberPsychology \& Behavior, 10, 545-551. https://doi.org/10.1089/cpb.2007.9992

Kraut, R., Patterson, M., Lundmark, V., Kiesler, S., Mukhopadhyay, T., \& Scherlis, W. (1998). Internet paradox: A social technology that reduces social involvement and psychological well-being? American Psychologist, 53, 1017-1031. 
Laconi, S., Rodgers, R. F., \& Chabrol, H. (2014). The measurement of Internet addiction: A critical review of existing scales and their psychometric properties. Computers in Human Behavior, 41, 190-202.

Lei, L., \& Wu, Y. (2007). Adolescents' paternal attachment and Internet use. CyberPsychology \& Behavior, 10(5), 633-639.

Lopez-Fernandez, O. (2018). Generalised versus specific Internet use-related addiction problems: A mixed methods study on Internet, gaming, and social networking behaviours. International Journal of Environmental Research and Public Health, 15(12), 2913. https://doi.org/10.3390/ijerph15122913

Lu, X., \& Yeo, K. J. (2015). Motivation of Internet use: Relation with pathological Internet use, gender and Internet activities. Jurnal Teknologi, 78(1), 181-188.

Malaysian Communications and Multimedia Commission. (2018). Internet Users Survey 2018. https://www.mcmc.gov.my/skmmgovmy/media/General/pdf/Internet-Users-Survey2018.pdf

Malaysian Communications and Multimedia Commission. (2020). Internet Users Survey 2020. https://www.mcmc.gov.my/skmmgovmy/media/General/pdf/IUS-2020-Report.pdf

Marcia, J. E. (1980). Identity in adolescence. In J. Adelson (Ed.). Handbook of adolescent psychology (pp. 159-187). New York: Wiley.

Matsuba, M. K. (2006). Searching for self and relationships online. CyberPsychology \& Behavior, 9, 275-84.

Mazalin, D., \& Moore, S. (2004). Internet use, identity development and social anxiety among young adults. Behaviour Change, 21, 90-102.

Morahan-Martin, J., \& Schumacher, P. (2000). Incidence and correlates of pathological Internet use among college students. Computers in Human Behavior, 16, 13-29.

Ng, C. G., Isa, S. M., Hashim, S., Pillai, K., \& Harbajan Singh, M. K. (2012). Validity of the Malay version of the Internet addiction test: $A$ study on a group of medical students in Malaysia. Asia-Pacific Journal of Public Health, 27(2), 2210-2219. https://doi.org/10.1177/1010539512447808

Nurhilyana, A., Zaid, M., \& Aminatul, M. (2013). Prevalence of Internet usage and academic purpose among pre-degree student: A case study. Proceeding of the International Conference on Social Science Research (ICSSR) 2013, pp. 1064-1070, 111-121. https://doi.org/10.1089/cpb.2006.9.95

Odacl, H., \& Kalkan, M. (2010). Problematic Internet use, loneliness and dating anxiety among young adult university students. Computers \& Education, 55, 1091-1097.

Öztürk, Ö, Odabasıoglu, G., Eraslan, D., Genç, Y., \& Kalyoncu, Ö. A. (2007). Internet addiction: Clinical aspects and treatment strategies. Journal of Dependence, 8, 36-41.

Pew Research Center. (2012, November 20). Parents, teens and online privacy: Main report. http://www.pewlnternet.org/2012/11/20/main-report-10/

Reid, E. (1998). The self and the Internet: Variations on the illusion of oneself. In J. Gackenbach (Ed.). Psychology and the Internet: Intrapersonal, interpersonal, and transpersonal implications (pp. 29-41). San Diego, CA: Academic Press.

Roslan, H. (2015). Analysis of Internet addiction and usage quality among malaysian students. Jurnal UMP Social Sciences and Technology Management, 3(2), 516-520.

Rosliza, A. M., Ragubathi, M. N., Mohamad Yusoff, M. K. A., \& Shaharuddin, M. S. (2018). Internet addiction among undergraduate students: Evidence from a Malaysian public university. International Medical Journal of Malaysia, 17(2), 41-48. 
Salehi, M., Khalili, N. M., Hojjat, S. K., Salehi, M., \& Danesh, A. (2014). Prevalence of Internet addiction and associated factors among medical students from Mashhad, Iran in 2013. Iranian Red Crescent Medical Journal, 16(5), Article e17256. https://doi.org/10.5812/ircmj.17256

Siraj, H. H., Salam, A., Hasan, N. A. B., Jin, T. H., Roslan, R. B., \& Othman, M. N. B. (2015). Internet usage and academic performance: A study in a Malaysian public university. International Medical Journal, 22(2), 83-86.

Skinner, B. F. (1948). 'Superstition' in the pigeon. Journal of Experimental Psychology, 38(2), 168-172.

Spada, M. M. (2014). An overview of problematic Internet use. Addictive Behaviors, 39(1), 36. https://doi.org/10.1016/j.addbeh.2013.09.007

Subrahmanyam, K., Kraut, R., Greenfield, P. M., \& Gross, E. F. (2001). New forms of electronic media: The impact of interactive games and the Internet on cognition, socialization, and behavior. In D. L. Singer \& J. L. Singer (Eds.), Handbook of children and the media (pp. 73-99). Thousand Oaks, CA: Sage.

Sutapat, S., Manee, P., Pattaraporn, H., Pimolpun, K., Nahathai, W., \& Tinakon, W. (2018). Prevalence, associated factors and impact of loneliness and interpersonal problems on Internet addiction: A study in Chiang Mai medical students. Asian Journal of Psychiatry, 31, 2-7.

Teong V. K., \& Ang, C. H. M. (2016). Internet use and addiction among students in Malaysian public universities in east Malaysia: Some empirical evidence. Journal of Management Research, 8(2), 31-47.

Teo, T. S. H. (2001). Demographic and motivation variables associated with Internet usage activities. Internet research: Electronic networking applications and policy, 11(2), 125137.

Tong, W.-T., Islam, M. A., Low, W. Y., Choo, W. Y., \& Abdullah, A. (2019). Prevalence and Determinants of Pathological Internet Use among Undergraduate Students in a Public University in Malaysia. The Journal of Behavioral Science, 14(1), 63-83. https://so06.tcithaijo.org/index.php/IJBS/article/view/141412

Valkenburg, P. M., \& Peter, J. (2008). Adolescents' identity experiments on the Internet: Consequences for social competence and self-concept unity. Communication Research, 35(2), 208-231. https://doi.org/10.1177/0093650207313164

Valkenburg, P. M., \& Peter, J. (2011). Online communication among adolescents: An integrated model of its attraction, opportunities, and risks. Journal of Adolescent Health, 48(2), 121-127. https://doi.org/10.1016/j.jadohealth.2010.08.020

Vo-Jutabha, E. D., Dinh, K. T., McHale, J. P., \& Valsiner, J. (2009). A qualitative analysis of Vietnamese adolescent identity exploration within and outside an ethnic enclave. Journal of Youth and Adolescence, 38(5), 672-690.

Wallace, P. (2014). Internet addiction disorder and youth. EMBO reports, 15(1), 12-16.

Wanajak, K. (2011). Internet use and its impact on secondary school students in Chiang Mai, Thailand. [Doctoral dissertation, Edith Cowan University]. Research Online Institutional Repository. https://ro.ecu.edu.au/theses/394

Willoughby, T. (2008). A short-term longitudinal study of Internet and computer game use by adolescent boys and girls: Prevalence, frequency of use, and psychosocial predictors. Developmental Psychology, 44, 195-204. https://doi.org/10.1037/0012-1649.44.1.195 
Young, K. S. (1999). Internet addiction: Symptoms, evaluation and treatment. In L. Van de Creek, \& T. Jackson (Eds.). Innovations in clinical practice: A source book (Vol. 17; pp. 1931). Sarasota, FL: Professional Resource Press.

Yu, L., \& Shek, D. T. (2013). Internet addiction in Hong Kong adolescents: A three-year longitudinal study [Supplement material]. Journal of Pediatric \& Adolescent Gynecology, 26(3), S10-S17. https://doi.org/10.1016/j.jpag.2013.03.010

Yu, T., Zong, X. G., Jie, R. S., Yu, L. B., Pi, G. H., Peng, W., \& Feng, Q. G. (2018). Bidirectional mediating role of loneliness in the association between shyness and generalized pathological internet use in chinese university students: A longitudinal cross-lagged analysis. The Journal of Psychology, 152(8), 529-547.

https://doi.org/10.1080/00223980.2018.14683 